\title{
Contamination effects study in the centrifugal compressor flow stage by means of numerical simulation methods
}

\author{
A.A. Aksenov ${ }^{1, *}, Y u . V . K_{0 z h u k h o v}{ }^{1}, A . A$. Lebedev $^{1}, A . Y$ Y Petrov $^{1}$, and Minh Hai Nguyen² \\ ${ }^{1}$ Peter the Great St. Petersburg Polytechnic University Federal State Autonomous Educational Institution of Higher Education, St. \\ Petersburg, Russia. \\ ${ }^{2}$ Petrovietnam Exploration Production Corporation, Ho Chi Minh City, Viet Nam
}

\begin{abstract}
At the moment there is no effective way to clean the flow of the turbine unit, which is justified from an economic point of view. It is important to understand how deposits affect compressor performance and the need to clean out contaminants. In the available literature, such studies are not described. The computational model of a stage domain for the study includes the following elements: inlet pipe, impeller, bladeless diffuser, swivel elbow, backward guide apparatus, outlet pipe. For calculations, the computational fluid dynamics methods in the Ansys software package were used. A numerical experiment was carried out in six mass flow rate variants, two impeller revolutions variants, and three different sediment thicknesses in the flow part variants. Based on the numerical experiment results, the calculated machine operating modes characteristics are constructed. The analysis revealed that the studied deposits cause a drop in the stage characteristics by $1.5-2 \%$. Losses in the stage increase proportionately to the thickness of deposits in the compressor flow part.
\end{abstract}

\section{Introduction}

Centrifugal compressors have found the widest application in power engineering. In modern gastransport networks, centrifugal compressors are the main equipment for gas compression. Despite the filtering equipment presence at an inlet to the compressor, its flow-through part is contaminated with aerosols present in the environment, as well as various contaminants (oil, soot, drip, etc.) allocated by various nodes of the unit itself. In the literature available, such studies are not described. It is very important to understand exactly how deposits affect compressor characteristics, and the need for cleaning the contaminants. At the moment there is no effective cleaning method, which would justify itself from an economic view point [1]. One of the simplest methods is mechanical compressor flow part cleaning. This method is quite effective, but requires complete unit stoppage and partial disassembly. This involves some difficulties, the gas transport shutdown since causes economic loss, as well as a reverse assembly of the machine, in which, for example, it is possible to improperly perform balancing, which will lead to other problems. The second method is special pumping composition through a turbine unit flowing part. This method does not require stopping the machine, but does not guarantee a flow section complete cleaning, since if the composition is excessively aggressive, the compressor working part may be a subject to destruction.

The objectives of this work:
1. Sediments effects investigation in a centrifugal compressor flow part and the rationale for cleaning from an economic point of view.

\section{Methods}

The study was carried out on a real prototype stage centrifugal compressor, using the software package ANSYS. The calculation involved the detailed spatial computer model use with a grid of discretization [2-11] necessary for solving this problem, and real gas parameters [12] were used as working fluid, which directly leads to the increase in the results obtained accuracy. The gas composition is shown in Table 1 . Viscous gas flow numerical simulation was carried out with six different mass flow options, from $28 \mathrm{~kg} / \mathrm{s}$ to 33 $\mathrm{kg} / \mathrm{s}$, and also with two rotor speeds, at nominal speed of $10600 \mathrm{rpm}$ and at $10000 \mathrm{rpm}$. The depositions were taken with a thickness $\delta=2 \mathrm{~mm}$ and $3 \mathrm{~mm}$, and their scheme is shown in Fig. 1.The deposits position was taken based on the using compressors practice. In the simulation, the SST turbulence model was used [13-20], and the grid elements total number exceeded 1 million. In the results processing, pressure and useful-action coefficient were calculated by the formulas:

$$
\psi_{n}=\frac{h_{p}}{U_{2}^{2}}
$$

\footnotetext{
* Corresponding author: aksenovaax@mail.ru
} 


$$
\eta_{p}=\frac{h_{\Pi}}{h_{i}-h_{d}}
$$

Where, $h_{p}$ - is the polytrophic head, $\mathrm{J} / \mathrm{kg} ; h_{i}-$ is the internal head, $\mathrm{J} / \mathrm{kg} ; h_{d}-$ is the dynamic head, $\mathrm{J} / \mathrm{kg}$, pressure $\mathrm{J} / \mathrm{kg}$, in the above expressions are determined by the following formulas:

$$
h_{p}=\frac{n}{n-1} R T_{0}\left[\left(\frac{p_{i}}{p_{0}}\right)^{\frac{n-1}{n}}-1\right]
$$

The exponent $n /(n-1)$ is determined by the formula:

$$
\frac{n}{n-1}=\log \frac{p_{i}}{p_{0}} / \log \frac{T_{i}}{T_{0}}
$$

The dynamic head $h_{d}, \mathrm{~J} / \mathrm{kg}$, is determined by the formula:

$$
h_{d}=\frac{c_{i}^{2}-c_{0}^{2}}{2}
$$

Where, $c_{i}$ and $c_{o}-$ are the velocities in the corresponding sections, $\mathrm{m} / \mathrm{s}$;

$$
h_{i}=h_{T}+h_{d f}+h_{l}
$$

here $h_{t}$ is the theoretical head, $\mathrm{J} / \mathrm{kg} ; h_{d f}-$ disk friction pressure, J/kg; $h_{l}$ - leakage pressure, $\mathrm{J} / \mathrm{kg}$. These characteristics determine compressor efficiency and pressure, the zone of its stable operation.

Table 1. - The gas mixture's composition.

\begin{tabular}{|c|c|}
\hline Component name & Share, \%Mol. \\
\hline Helium,\% & 0.00565 \\
\hline Hydrogen,\% & 0.00155 \\
\hline Oxygen,\% $\%$ & less 0.005 \\
\hline Carbondioxide,\% & 0.34750 \\
\hline Nitrogen, $\%$ & 0.41900 \\
\hline Methane,\% & 94.78500 \\
\hline Ethane,\% $\%$ & 1.5000 \\
\hline Propane, $\%$ & 1.23500 \\
\hline i-Butane, $\%$ & 0.42900 \\
\hline n-Butane, $\%$ & 0.45850 \\
\hline neo-Pentane, $\%$ & 0.00750 \\
\hline i-Pentane, $\%$ & 0.14200 \\
\hline n-Pentane, $\%$ & 0.10200 \\
\hline Hexanes, $\%$ & 0.07550 \\
\hline Heptanes, $\%$ & 0.02990 \\
\hline Octanes, $\%$ & 0.00875 \\
\hline Densityat kg/m3 0.725 \\
\hline
\end{tabular}

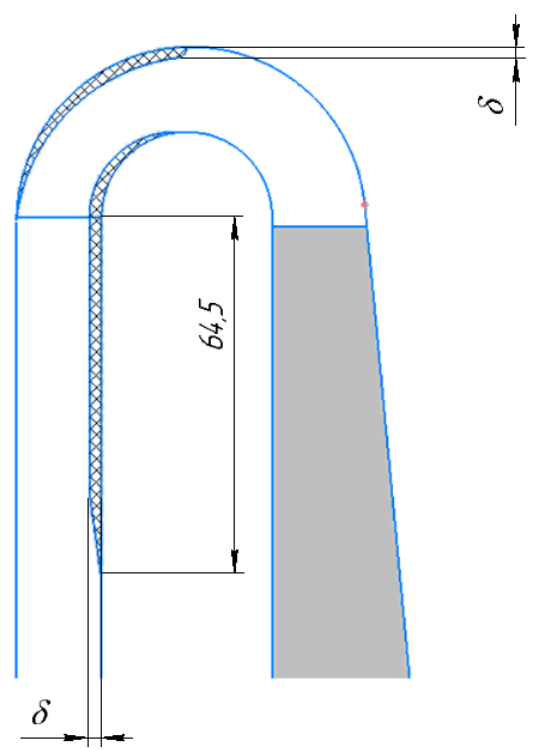

Fig. 1. Deposits scheme in a centrifugal compressor stage flow part.

\section{Results}

Table 2 presents the calculating results the gasdynamical parameters a centrifugal compressor stage at $\mathrm{n}=10600$ without contamination in the flow section, as well as the processing results these data.

Table 3 presents the calculating results the gasdynamical parameters a centrifugal compressor stage at $\mathrm{n}=10600$ with contamination in the flowing part $2 \mathrm{~mm}$ thick, as well as the processing results these data.

Table 4 presents the calculating results the gasdynamical parameters a centrifugal compressor stage at $\mathrm{n}=10600$ with contamination in the flowing part $3 \mathrm{~mm}$ thick, as well as the processing results these data.

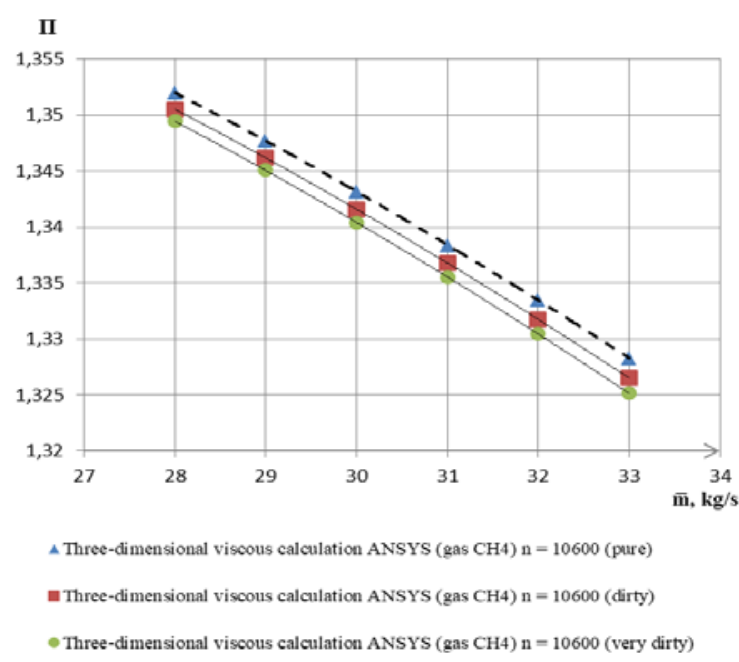

Fig. 2. Deposits effect on a compressor stage efficiency at $n=$ 10600 . 
Table 2. - Three-dimensional viscous ANSYS calculation at $\mathrm{n}=10600$ with thickness deposits $\delta=0 \mathrm{~mm}$.

\begin{tabular}{|c|c|l|c|c|c|c|c|c|c|c|}
\hline$\overline{\boldsymbol{m}}$ & $\boldsymbol{\Delta T}$ & $\boldsymbol{P}_{\boldsymbol{k}}$ & $\boldsymbol{\Pi}$ & $\boldsymbol{\Pi}_{\boldsymbol{k}}$ & $\boldsymbol{\eta}_{\boldsymbol{p}}$ & $\boldsymbol{\psi}_{\boldsymbol{i}}$ & $\boldsymbol{\zeta}_{2-4}$ & $\boldsymbol{\zeta}_{4-5}$ & $\boldsymbol{\zeta}_{5-\boldsymbol{k}}$ & $\boldsymbol{\zeta}_{2-\boldsymbol{k}}$ \\
\hline 28 & 23.72 & 240384 & 1.352 & 1.2375 & 0.9094 & 0.7199 & 0.11171 & 0.08410 & 0.2692 & 0.4276 \\
\hline 29 & 23.46 & 239398 & 1.347 & 1.2354 & 0.9095 & 0.7127 & 0.10893 & 0.08176 & 0.2639 & 0.4141 \\
\hline 30 & 23.19 & 238362 & 1.343 & 1.2332 & 0.9091 & 0.7055 & 0.10653 & 0.07962 & 0.2600 & 0.4027 \\
\hline 31 & 22.91 & 237282 & 1.338 & 1.2309 & 0.9083 & 0.6982 & 0.10419 & 0.07789 & 0.2568 & 0.3924 \\
\hline 32 & 22.63 & 236159 & 1.333 & 1.2285 & 0.9072 & 0.6909 & 0.10143 & 0.07624 & 0.2541 & 0.3822 \\
\hline 33 & 22.33 & 234992 & 1.328 & 1.2259 & 0.9057 & 0.6836 & 0.09887 & 0.07485 & 0.2524 & 0.3732 \\
\hline
\end{tabular}

Table 3. - Three-dimensional viscous ANSYS calculation at $\mathrm{n}=10600$ with thickness deposits $\delta=2 \mathrm{~mm}$.

\begin{tabular}{|c|c|c|c|c|c|c|c|c|c|c|}
\hline $\bar{m}$ & $\Delta T$ & $P_{k}$ & II & $\Pi_{k}$ & $\eta_{p}$ & $\psi_{i}$ & $\zeta_{2-4}$ & $\zeta_{4-5}$ & $\zeta_{5-k}$ & $\zeta_{2-k}$ \\
\hline 28 & 23.71 & 240118 & 1.35 & 1.2372 & 0.9062 & 0.7199 & 0.1168 & 0.0872 & 0.2678 & 0.4446 \\
\hline 29 & 23.45 & 239127 & 1.346 & 1.2352 & 0.9061 & 0.7127 & 0.1140 & 0.0851 & 0.2630 & 0.4320 \\
\hline 30 & 23.17 & 238084 & 1.341 & 1.2330 & 0.9056 & 0.7055 & 0.1113 & 0.0835 & 0.2592 & 0.420 \\
\hline 31 & 22.89 & 236994 & 1.336 & 1.2307 & 0.9046 & 0.6983 & 0.1089 & 0.0817 & 0.2561 & 0.4103 \\
\hline 32 & 22.61 & 23585 & 1.331 & 1.2283 & 0.9033 & 0.691 & 0.1063 & 0.0801 & 0.2538 & 0.4005 \\
\hline 33 & 22.32 & 234678 & 1.326 & 1.2257 & 0.9016 & 0.6836 & 0.1040 & 0.0784 & 0.2527 & 0.3922 \\
\hline
\end{tabular}

Table 4. - Three-dimensional viscous ANSYS calculation at $\mathrm{n}=10600$ with thickness deposits $\delta=3 \mathrm{~mm}$.

\begin{tabular}{|c|c|c|c|c|c|c|c|c|c|c|}
\hline$\overline{\boldsymbol{m}}$ & \multicolumn{1}{|c|}{$\boldsymbol{T}$} & $\boldsymbol{P}_{\boldsymbol{k}}$ & $\boldsymbol{\Pi}$ & $\boldsymbol{\Pi}_{\boldsymbol{k}}$ & $\boldsymbol{\eta}_{\boldsymbol{p}}$ & $\boldsymbol{\psi}_{\boldsymbol{i}}$ & $\boldsymbol{\zeta}_{2-4}$ & $\boldsymbol{\zeta}_{4-5}$ & $\boldsymbol{\zeta}_{5-\boldsymbol{k}}$ & $\boldsymbol{\zeta}_{2-\boldsymbol{k}}$ \\
\hline 28 & 23.7 & 239928 & 1.349 & 1.2374 & 0.9041 & 0.7199 & 0.1198 & 0.0917 & 0.2693 & 0.4581 \\
\hline 29 & 23.43 & 238928 & 1.345 & 1.2353 & 0.9038 & 0.7127 & 0.1169 & 0.0899 & 0.2643 & 0.4457 \\
\hline 30 & 23.16 & 237875 & 1.34 & 1.2331 & 0.9031 & 0.7055 & 0.1144 & 0.0882 & 0.2603 & 0.4348 \\
\hline 31 & 22.88 & 236774 & 1.335 & 1.2308 & 0.9020 & 0.6983 & 0.1121 & 0.0866 & 0.2570 & 0.4249 \\
\hline 32 & 22.6 & 235627 & 1.33 & 1.2284 & 0.9005 & 0.6909 & 0.1096 & 0.0850 & 0.2548 & 0.4158 \\
\hline 33 & 22.3 & 234435 & 1.325 & 1.2258 & 0.8986 & 0.6836 & 0.1075 & 0.0834 & 0.2541 & 0.4080 \\
\hline
\end{tabular}

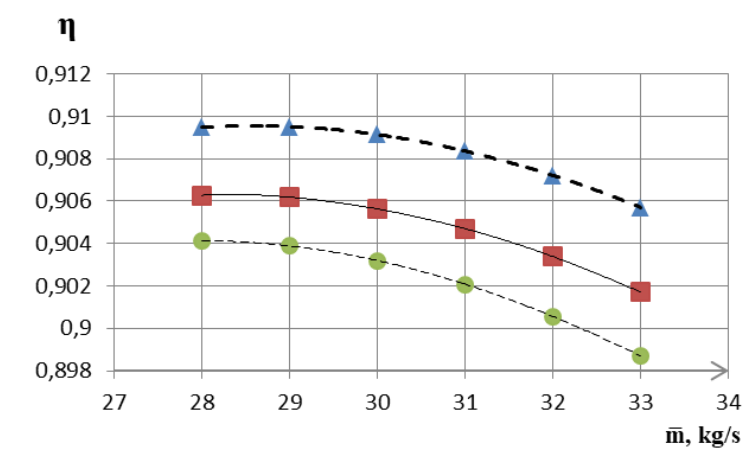

$\Delta$ Three-dimensional viscous calculation ANSYS (gas CH4) $\mathrm{n}=10600$ (pure)

"Three-dimensional viscous calculation ANSYS (gas CH4) $\mathrm{n}=10600$ (dirty)

- Three-dimensional viscous calculation ANSYS (gas CH4) $n=10600$ (very dirty)

Fig. 3. Deposits effect on a compressor stage efficiency at $\mathrm{n}=$ 10600.

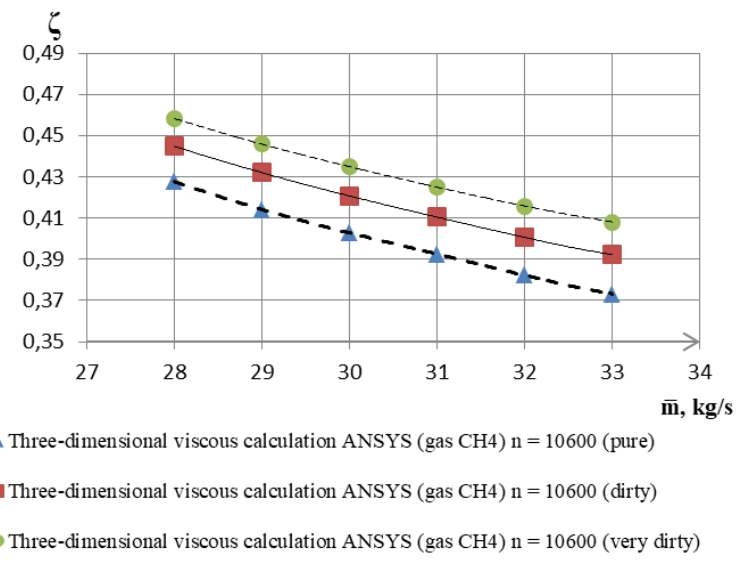

Fig. 4. Deposits effect on a compressor stage efficiency at $n=$ 10600.

Table 5 presents the calculating results the gasdynamic parameters a centrifugal compressor stage $n$ $=10000$ without contamination in the flowing part, as well as the processing results these data.

Table 6 presents the calculating results the gasdynamical parameters a centrifugal compressor stage at $\mathrm{n}=10000$ with contamination in the flowing part $2 \mathrm{~mm}$ thick, as well as the processing results these data. 
Table 5. - Three-dimensional viscous ANSYS calculation at $\mathrm{n}=10000$ with thickness deposits $\delta=0 \mathrm{~mm}$.

\begin{tabular}{|c|c|c|l|l|l|l|l|l|l|l|}
\hline$\overline{\boldsymbol{m}}$ & $\boldsymbol{\Delta} \boldsymbol{T}$ & $\boldsymbol{P}_{\boldsymbol{k}}$ & $\boldsymbol{\Pi}$ & \multicolumn{1}{c}{$\boldsymbol{\Pi}_{\boldsymbol{k}}$} & $\boldsymbol{\boldsymbol { \eta } _ { \boldsymbol { p } }}$ & $\boldsymbol{\psi}_{\boldsymbol{i}}$ & $\boldsymbol{\zeta}_{2-4}$ & $\boldsymbol{\zeta}_{4-5}$ & $\boldsymbol{\zeta}_{5-\boldsymbol{k}}$ & $\boldsymbol{\zeta}_{2-\boldsymbol{k}}$ \\
\hline 28 & 20.58 & 231113 & 1.299 & 1.204655 & 0.9082 & 0.7047 & 0.1042 & 0.0803 & 0.2614 & 0.399 \\
\hline 29 & 20.31 & 230101 & 1.295 & 1.202417 & 0.9073 & 0.696 & 0.1021 & 0.0780 & 0.2577 & 0.3888 \\
\hline 30 & 20.04 & 229040 & 1.29 & 1.200043 & 0.9060 & 0.6891 & 0.100 & 0.0760 & 0.2547 & 0.3796 \\
\hline 31 & 19.76 & 227942 & 1.285 & 1.197581 & 0.9043 & 0.6812 & 0.0989 & 0.0745 & 0.2526 & 0.3717 \\
\hline 32 & 19.48 & 226805 & 1.28 & 1.195004 & 0.9022 & 0.6733 & 0.0973 & 0.0729 & 0.2523 & 0.3653 \\
\hline 33 & 19.17 & 225626 & 1.275 & 1.192304 & 0.8997 & 0.6653 & 0.0958 & 0.0709 & 0.2541 & 0.3598 \\
\hline
\end{tabular}

Table 6. - Three-dimensional viscous ANSYS calculation at $\mathrm{n}=10000$ with thickness deposits $\delta=2 \mathrm{~mm}$.

\begin{tabular}{|c|c|c|c|c|c|c|c|c|c|c|}
\hline $\bar{m}$ & $\Delta T$ & $P_{k}$ & $\Pi$ & $\Pi_{k}$ & $\eta_{p}$ & $\psi_{i}$ & $\zeta_{2-4}$ & $\zeta_{4-5}$ & $\zeta_{5-k}$ & $\zeta_{2-k}$ \\
\hline 28 & 20.57 & 230871 & 1.298 & 1.204463 & 0.9047 & 0.7047 & 0.1097 & 0.0832 & 0.260 & 0.4174 \\
\hline 29 & 20.3 & 229847 & 1.293 & 1.202236 & 0.9036 & 0.697 & 0.1076 & 0.0812 & 0.2571 & 0.4071 \\
\hline 30 & 20.03 & 228781 & 1.289 & 1.199896 & 0.9022 & 0.689 & 0.1056 & 0.0798 & 0.2543 & 0.3983 \\
\hline 31 & 19.74 & 227671 & 1.284 & 1.197434 & 0.9002 & 0.681 & 0.103 & 0.0786 & 0.252 & 0.3908 \\
\hline 32 & 19.46 & 226519 & 1.279 & 1.194856 & 0.8979 & 0.6734 & 0.1024 & 0.0768 & 0.2531 & 0.3846 \\
\hline 33 & 19.15 & 225325 & 1.273 & 1.19215 & 0.8952 & 0.6654 & 0.1011 & 0.0746 & 0.2555 & 0.380 \\
\hline
\end{tabular}

Table 7. - Three-dimensional viscous ANSYS calculation at $\mathrm{n}=10000$ with thickness deposits $\delta=3 \mathrm{~mm}$.

\begin{tabular}{|c|c|l|l|l|l|l|l|l|l|}
\hline $\bar{m}$ & \multicolumn{1}{|c|}{$P_{k}$} & \multicolumn{1}{c|}{$\Pi$} & \multicolumn{1}{c|}{$\Pi_{k}$} & \multicolumn{1}{c|}{$\eta_{p}$} & $\psi_{i}$ & $\zeta_{2-4}$ & $\zeta_{4-5}$ & $\zeta_{5-k}$ \\
\hline 28 & 20.56 & 230686 & 1.297 & 1.204554 & 0.90221 & 0.7047 & 0.1130 & 0.0875 & 0.2618 \\
\hline 29 & 20.29 & 229651 & 1.292 & 1.202322 & 0.900945 & 0.6969 & 0.1108 & 0.0861 & 0.2583 \\
\hline 30 & 20.01 & 228574 & 1.288 & 1.199982 & 0.899247 & 0.6891 & 0.1088 & 0.0850 & 0.2552 \\
\hline 31 & 19.73 & 227454 & 1.282 & 1.19752 & 0.897154 & 0.6812 & 0.1072 & 0.0839 & 0.2534 \\
\hline 32 & 19.44 & 226293 & 1.277 & 1.194943 & 0.894605 & 0.6733 & 0.1060 & 0.0818 & 0.2545 \\
\hline 33 & 19.14 & 225088 & 1.272 & 1.192236 & 0.891648 & 0.6653 & 0.1047 & 0.0800 & 0.2566 \\
\hline
\end{tabular}

Table 7 presents the calculating results the gasdynamical parameters a centrifugal compressor stage at $\mathrm{n}=10000$ with contamination in the flowing part $3 \mathrm{~mm}$ thick, as well as the processing results these data.

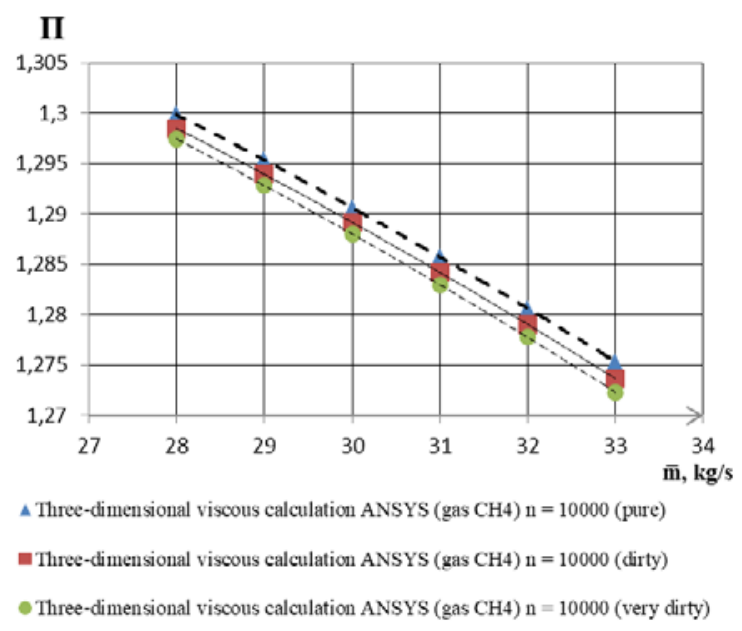

Fig. 5. Deposits effect on a compressor stage efficiency at $\mathrm{n}=$ 10000 .

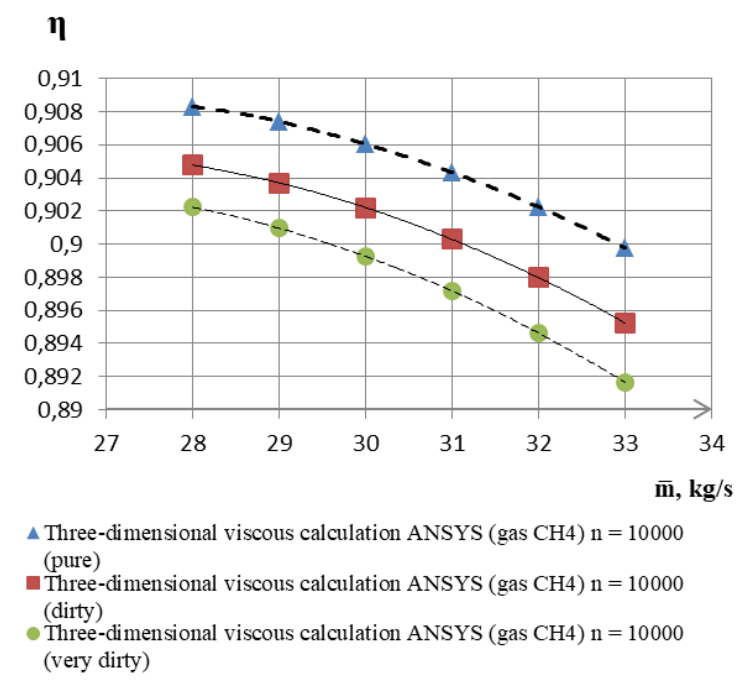

Fig. 6. Deposits effect on total loss in the compressor stage with $\mathrm{n}=10000$. 


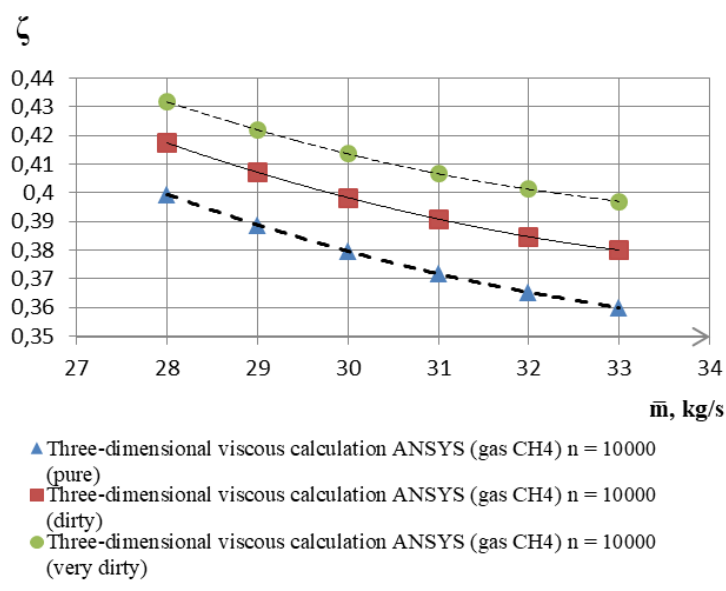

Fig. 7. Deposits effect on total loss in the compressor stage with $\mathrm{n}=10000$

As it can be seen from the graphs, the deposits presence in the compressor flowing part causes a drop in the compressor characteristics output, the drop lies within $1-2 \%$. The loss in the compressor stages increase in proportion to the deposits thickness in the flow part. The deposits thickness can't be more than certain; the flow velocity in the flowing part will not allow to detain the forming elements, and in the deposits presence, the velocity will only increase. However, the deposits presence in the flowing part not only affects the characteristics of the machine, but also is a particles source that is detached from the deposits under the flow influence. The dense particles presence in the flow can lead to damage surface of the blade, for example, the protective layer destruction, which will lead to corrosion, and, accordingly, to the working part replacement

\section{Conclusions}

As a result of the numerical study carried out in CFD for the this type stage and modes of operation, it has been shown that, in addition to the deposits effect on characteristics, other factors that may have a greater effect on the change in compressor performance during operation are to be considered.

\section{References}

1. R. Z. Ríos-Mercado and C. Borraz-Sánchez, "Optimization problems in natural gas transportation systems: A state-of-the-art review,” Applied Energy, vol. 147, pp. 536-555, $2015 . \quad$ DOI: 10.1016/j.apenergy.2015.03.017

2.Aksenov, A., Kozhukhov, Y., Sokolov, M., Simonov, A. Analysis and modernization of real gas thermodynamic calculation for turbocompressors and detander units. (2018) MATEC Web of Conferences, 245, article № 09005.
3.Yun V.K. The use of advanced technologies to increase the economic efficiency of a centrifugal compressor. Gas industry №9, 2014 c 68-71.2.

4.Danilishin, A.M., Kozhukhov, Y.V., Simonov, A.M. Gas-dynamic designing and profiling complex for the two-element centrifugal compressor stage with 3D impeller (2019) AIP Conference Proceedings, 2141, article № 030065, .

5.Ivanov, V.M., Kozhukhov, Y.V., Danilishin, A.M. Calculation of the impellers head characteristics of the low-flow centrifugal compressor stages based on quasithree-dimensional inviscid and viscous methods (2019) AIP Conference Proceedings, 2141, article № 030064, . 6.Yablokov, A., Yanin, I., Danilishin, A., Zuev, A. Ansys CFX numerical study of stages centrifugal compressor with low-flow rate coefficient. (2018) MATEC Web of Conferences, 245, article № 09002. DOI: $10.1051 /$ matecconf/201824509002

7. Zharkovskii, A.A., Pospelov, A.Y. Use of 3D Methods for Flow Analysis, Prediction of Characteristics, and Optimization of the Shape of Settings of Hydraulic Turbines. (2015) Power Technology and Engineering, 49 (1), pp. 27-32.

8. Neverov, V., Kozhukhov, Y., Kartashov, S., Ivanov, $\mathrm{V}$. The choice of key geometric parameters in the numerical optimization of centrifugal compressor impellers. (2018) MATEC Web of Conferences, 245, article № 09008 . 10.1051/matecconf/201824509008

9. Aksenov, A.A., Danilishin, A.M., Dubenko, A.M., Kozhukov, Y.V. Development of the virtual experimental bench on the basis of modernized research centrifugal compressor stage test unit with the 3D impeller.(2017) IOP Conference Series: Materials Science and Engineering, 232 (1), article № 012042. DOI: $10.1088 / 1757-899 X / 232 / 1 / 012042$

10. Zhurkin, N., Donskoj, A., Zharkovskij, A. Numeric modeling and estimating the performance characteristics of a pneumatic driven high pressure pump. (2018) MATEC Web of Conferences, 245, \# 09014. DOI: 10.1051/matecconf/201824509014.

11. J. Li, Y. Yin, S. Li, and J. Zhang, "Numerical simulation investigation on centrifugal compressor performance of turbocharger," Journal of Mechanical Science and Technology, vol. 27, no. 6, pp. 1597-1601, 2013.

12. Aksenov, A., Kozhukhov, Y., Sokolov, M., Simonov, A. Analysis and modernization of real gas thermodynamic calculation for turbocompressors and detander units. (2018) MATEC Web of Conferences, 245, статья № 09005.

DOI:0.1051/matecconf/201824509005

13. B. E. Launder and D. B. Spalding, "The numerical computation of turbulent flows," Computer Methods in Applied Mechanics and Engineering, vol. 3, no. 2, pp. 269-289, 1974. DOI: 10.1016/0045-7825(74)90029-2

14. M. V. Casey, P. Dalbert, and P. Roth, "The use of 3D viscous flow calculations in the design and analysis of industrial centrifugal compressors," Journal of Turbomachinery, vol. 114, no. 1, pp. 27-37, 1992. DOI: 10.1115/1.2927995 
15. Z. Guzović, M. Baburić, and D. Matijašević, "Comparison of flow characteristics of centrifugal compressors by numerical modelling of flow," Journal of Mechanical Engineering, vol. 51, no. 7-8, pp. 509-518, 2005.

16. Ivanov, E.A., Zharkovsky, A.A., Borshchev, I.O., Svoboda, D.G. Technique for axial pump characteristics predicting in CFD package Openfoam. AIP Conference Proceedings v.2141,\#030063. (2019). DOI: 10.1063/1.5122113..

17. R. C. Dean and Y. Senoo, "Rotating wakes in vaneless diffusers,” Journal of Basic Engineering, vol. 82, no. 3, pp. 563-570, 1960. DOI: 10.1115/1.3662659

18. M. Inoue and N. A. Cumpsty, "Experimental study of centrifugal impeller discharge flow in vaneless and vaned diffusers," Journal of Engineering for Gas Turbines and Power, vol. 106, no. 2, p. 455, 1984 DOI: 10.1115/1.3239588

19Pospelov, A.Y., Zharkovskii, A.A. Effect of the Parameters of a Computational Model on the Prediction of Hydraulic Turbine Characteristics. (2015) Power Technology and Engineering, 49 (3), pp. 159-164.

20. A.M. Simonov. Efficiency research and optimal design of high-pressure centrifugal compressor stages. P. 164 - 188. / Proceedings of the Scientific School of Compressor Engineering SPbSPU. Under the editorship of Professor Yu.B. Galerkin. - Publishing house SPbSPU, SPb, 2010 - 670 p. 